REVISTA X, Curitiba, volume 13,n.1, p. 161-167, 2018.

Dossiê Especial: Português como Língua Adicional em contextos de minorias:

(co)construindo sentidos a partir das margens

BIZON \& DINIZ (Orgs.)

\title{
BREVE MEMÓRIA DE UM APRENDIZ: UM OLHAR SOBRE MEUS CAMINHOS EM DIREÇÃO À LÍNGUA PORTUGUESA
}

\section{A Brief Memory of a Learner: a Glance at my Pathways Towards the Portuguese Language}

Sudly Amonsen Raphaël SAINTIL, Programa Emergencial Pró-Haiti - Unicamp ${ }^{1}$

\section{De onde parte a memória}

No dia 12 de janeiro de 2010, um terrível terremoto abalou o solo haitiano, deixando milhares de mortos e reduzindo a escombros boa parte da infraestrutura do país (hospitais, igrejas, vários campi universitários e até o palácio nacional). Diante dessa catástrofe sem precedentes na história do Haiti, países do mundo inteiro, dentre os quais o Brasil, se apressaram em prestar ajuda para a "(re)construção" do país em vários domínios. Nessa mesma linha de raciocínio, o governo brasileiro ofereceu apoio ao Haiti em algumas áreas, dentre as quais Saúde e Educação.

Assim, a CAPES, em conjunto com a Secretaria de Educação Superior (SESu) do Ministério da Educação (MEC) e com o Ministério das Relações Exteriores (MRE), criou o Programa Emergencial em Educação Superior Pró-Haiti-Graduação, cujo principal objetivo foi "contribuir para a reconstrução do Haiti por meio de apoio à formação de recursos humanos [e] apoiar a reestruturação das instituições de ensino superior (IES) daquele país" ${ }^{2}$. O programa baseia-se na concessão de bolsas de estudos a estudantes das instituições de ensino superior de Porto Príncipe em instituições de ensino superior brasileiras (IES).

Inicialmente, essa iniciativa foi planejada para acolher 500 alunos haitianos em IES brasileiras, dentro de um sistema de graduação-sanduíche que garantiria, além de auxilio de deslocamento (passagem área vinda ao Brasil e volta ao Haiti no final dos seus respectivos cursos), um auxílio de instalação e uma bolsa mensal. Em agosto de

\footnotetext{
${ }^{1}$ Graduado em Linguística e Graduando em Letras. Email: sudlysaintil@gmail.com.

2 Disponível em: <http://www.capes.gov.br/cooperacao-internacional/haiti/pro-haiti>. Acesso em: 15 mar. 2018.
} 
REVISTA X, Curitiba, volume 13,n.1,p.161-167, 2018.

Dossiê Especial: Português como Língua Adicional em contextos de minorias:

(co)construindo sentidos a partir das margens

BIZON \& DINIZ (Orgs.)

2011, após o processo de seleção da CAPES, chegaram 78 estudantes, que foram alocados em quatro universidades brasileiras (estaduais e federais), dentre elas, a Universidade Estadual de Campinas (Unicamp).

Faço parte desse grupo e, neste relato, compartilho minha experiência de aprendizagem da língua portuguesa no contexto mencionado. Com este relato, busco visibilizar algumas questões relacionadas às políticas de acolhimento de ensino de português para estudantes estrangeiros oriundos de países periféricos. Considero que colocar em discussão tais questões é de extrema importância num momento em que o debate sobre a internacionalização das universidades brasileiras está cada vez mais forte.

\section{Um ponto anterior na memória}

Antes de prosseguir com o relato, creio ser relevante falar um pouco sobre a "entrada" da língua portuguesa no Haiti. Até o final da década de noventa do século $\mathrm{XX}$, a língua portuguesa não fazia parte do mercado linguístico haitiano. A partir de 2004, com a presença do Brasil na liderança da MINUSTAH ${ }^{3}$, ela vem, aos poucos, ganhando espaço. Porém, até 2011, quando os estudantes do Programa Emergencial Pró-Haiti chegaram ao Brasil, sua difusão era bem restrita, o que explica o fato de a quase totalidade desse grupo de jovens não saber praticamente nada de português, língua na qual seriam ministradas as aulas de seus cursos no Brasil. Para tanto, logo ao chegarem à universidade - e aqui, assumindo efetivamente meu lugar nesse grupo, digo ao chegarmos à universidade -, fomos matriculados em um curso intensivo de língua portuguesa antes do início das aulas de graduação. Esse curso teve a duração de um semestre, de agosto a novembro de 2011.

\footnotetext{
${ }^{3}$ A MINUSTAH ou Missão das Nações Unidas para a Estabilização no Haiti (sigla derivada do francês: Mission des Nations Unies pour la Stabilisation en Haïti) é uma missão de paz criada pelo Conselho de Segurança das Nações Unidas (CSONU) em 30 de abril de 2004, por meio da resolução 1542, para "restaurar a ordem" no Haiti, após um período de insurgência e após a deposição do presidente Jean-Bertrand Aristide. O CSONU decidiu pela extinção da missão em 13 de abril de 2017, num processo gradual de remoção até o esvaziamento do contingente militar encerrado em 15 de outubro do mesmo ano. Disponível em:<http://www.defesa.gov.br/relacoesinternacionais/missoes-de-paz/o-brasil-na-minustah-haiti.> Acesso em: 17 abr. 2018.
} 
REVISTA X, Curitiba, volume 13,n.1,p.161-167, 2018.

Dossiê Especial: Português como Língua Adicional em contextos de minorias:

(co)construindo sentidos a partir das margens

BIZON \& DINIZ (Orgs.)

A relação entre o Brasil e o Haiti foi um tanto quanto tímida até a entrada do Brasil na liderança da MINUSTAH, em 2004, quando passaram a ser implementadas certas ações significativas do Brasil no Haiti, tanto da parte do próprio Estado brasileiro quanto da sociedade civil brasileira, principalmente por meio de $\mathrm{ONGs}^{4}$. Dentre essas ações, destaca-se a fundação, em 2008, do Centro Cultural Brasil-Haiti Celso Ortega Terra (CCBH), ligado à embaixada do Brasil no Haiti. O nome do centro foi dado em homenagem a um secretário haitiano da embaixada do Brasil, morto em Porto Príncipe, em 25 de outubro de 1967. Assim como outros centros congêneres, espalhados por diferentes países, o CCBH se dedica ao ensino sistemático do português brasileiro no exterior, bem como à difusão de construções culturais brasileiras. São inúmeras as atividades promovidas: de espetáculos teatrais a saraus poéticos e musicais, de cursos de capoeira à celebração de festividades e tradições culturais expressas no calendário do Brasil, de aulas a conferências e seminários ${ }^{5}$. Segundo o coordenador do centro, se, no início, eram apenas universitários que o frequentavam, hoje em dia, pode-se encontrar uma diversidade de público haitiano interessado nessas ações, de diferentes classes sociais e idades. Vale registrar que, no início de 2018, para ajudar a responder a essa crescente demanda, a Unicamp fez uma doação de livros literários e didáticos à biblioteca do centro ${ }^{6}$.

Paralelamente às atividades do CCBH, lembro que, em 2008, Normelia Parisse, a coordenadora desse centro, apresentava emissões radiofônicas com o objetivo de mostrar ao público aspectos da cultura brasileira através de músicas. Além disso, graças à iniciativa dessa coordenadora, foi aberta uma cadeira de língua portuguesa no Departamento de Línguas da Escola Normal Superior da Universidade Estadual do Haiti, em que essa mesma coordenadora foi contratada como professora.

\footnotetext{
${ }^{4}$ São exemplos de ONGs atuantes no Haiti a Viva Rio (Disponivel em<http://www.vivario.org.br/viva-rio-no-haiti/. Acesso em: 10 fev. 2018.), a People For Haiti (http://www.peopleforhaiti.com/>. Acesso em: 10 fev. 2018) e a Vidas Recicladas (http://vidasrecicladas.org/projeto-haiti/. Acesso em: $10 \mathrm{fev}$. 2018), apenas para citar algumas.

${ }^{5}$ FELISBERTO, Jordana Peixoto. A Língua Portuguesa do Brasil e o Novo Cenário Econômico Mundial. TCC, Brasília: Universidade de Brasília, Instituto de Letras - IL. Departamento de Linguística, Português e Línguas Clássicas - LIP, 2012. Disponível em: <http://bdm.unb.br/bitstream/ 10483/3821/ 1/ 2012 _Jord a na Pei xo to Fe lis berto.pdf $>$. Acesso em: 19 jan. 2018.

${ }^{6}$ Disponível em:<https://www.unicamp.br/unicamp/noticias/2018/01/15/editora-da-unicamp-faz-doacao-de-livros-bi blioteca-publica-no-haiti>Acesso em: 17 abril 2018.
} 
REVISTA X, Curitiba, volume 13,n.1,p. 161-167, 2018.

Dossiê Especial: Português como Língua Adicional em contextos de minorias:

(co)construindo sentidos a partir das margens

BIZON \& DINIZ (Orgs.)

$\mathrm{Eu}$ fui da primeira turma dessa faculdade a receber as primeiras aulas de português. Naquela época, excetuando-se a possibilidade de trabalhar como intérprete para os soldados brasileiros da MINUSTAH ou de missionários brasileiros, em quase nenhuma esfera da realidade haitiana o português podia ser usado. $\mathrm{O}$ fato de o português ter ocupado, naquela época, uma posição desfavorável em relação às outras línguas presentes no cenário linguístico do Haiti influenciou bastante o processo de sua aprendizagem por boa parte da turma de estudantes. Sabemos que há uma estreita relação entre as representações construídas em torno de uma língua em questão, o grau de interesse das pessoas em aprendê-la e as chances de êxito em sua aprendizagem. Dessa forma, em várias aulas, observou-se uma falta de participação dos alunos, com pouco interesse de uma parte da turma. Eu próprio, sinceramente, sem vislumbrar uma utilidade do português para minha formação pessoal e acadêmica, assistia às aulas porque queria ter um bom histórico escolar, e não porque tinha efetivo interesse pela língua. Acho que isso teve a ver com o que o Brasil representava para mim, até porque, naquela época, o Brasil era apenas futebol e Rio de Janeiro, cidade que sempre sonhei em um dia conhecer.

\section{Aproximando a memória do presente}

Sempre quis ter a experiência de estudar num país estrangeiro, independentemente de qual fosse. Foi assim que, em 2010, depois de dois anos de aulas de português, por meio das quais comecei a nutrir um certo interesse pela cultura do Brasil em sua diversidade, descobri o edital da CAPES convidando haitianos a cursarem 18 meses de estudos em universidades brasileiras por meio do Programa Emergencial Pró-Haiti. Aproximadamente um ano após minha candidatura, a lista dos estudantes selecionados saiu. E eu estava entre eles.

Outra jovem selecionada e eu éramos os dois únicos, de um grupo de 40 estudantes, a ter conhecimento básico da língua portuguesa antes de chegar ao Brasil, graças às aulas de português que havíamos tido no Haiti. Foi tal conhecimento que nos 
REVISTA X, Curitiba, volume 13,n.1,p. 161-167, 2018.

Dossiê Especial: Português como Língua Adicional em contextos de minorias:

(co)construindo sentidos a partir das margens

BIZON \& DINIZ (Orgs.)

ajudou a compreender alguma coisa quando aqui chegamos, e que nos possibilitou, em alguns contextos, ajudar outros colegas da turma.

Chegamos ao Brasil no dia 08 de agosto de 2011. Era uma segunda-feira. Na primeira semana, aproveitamos para compreender o espaço em que então nos encontrávamos e para resolver algumas formalidades da universidade e da polícia federal. Logo na semana seguinte, iniciamos as aulas de português com dedicação exclusiva e de maneira intensa. Estando no Brasil, meu interesse em me apropriar da língua mudou drasticamente, pois sabia que, além de ter que assistir às aulas exclusivamente em português, estava num contexto de imersão linguístico-cultural. $\mathrm{O}$ português era e é, definitivamente, um fator preponderante para a inserção e para o sucesso que sempre visei.

Os quarenta alunos foram divididos em duas turmas de vinte alunos, com dois professores principais em cada turma, e um assistente para tirar dúvidas. Além desses três formadores, cada aluno tinha direito a um tutor, cuja atribuição era auxiliar não somente com as aulas principais, mas também com questões da vida cotidiana dentro e fora da universidade, o que incluía o mercado, o banco, o hospital e vários outros espaços necessários à inclusão à nova vida. Também fazia parte do grupo uma mestranda em Antropologia que nos serviu de guia. Ela falava créole e auxiliou todos os estudantes haitianos em relação a problemas sociolinguísticos e culturais.

Todas as aulas desse grande projeto foram concebidas focalizando a língua não em uma concepção tradicional de ensino, em que a gramática costuma ser o centro, mas como discurso. Trabalhávamos a língua em suas diversas facetas de uso, tendo a gramática como subsídio para esses usos. Durante essas aulas, aprendi bastantes coisas sobre um Brasil em sua diversidade, numa clara tentativa dos docentes de não reduzir o Brasil a um todo homogêneo, sem levar em conta os diversos grupos que compõem esse país e suas complexidades.

Como parte das atividades do curso de português, além das aulas dentro de quatro paredes, assistimos a um jogo de futebol no estádio da Ponte Preta e a uma peça de teatro no Teatro Municipal de Campinas. Também realizamos uma visita guiada à cidade de São Paulo, onde conhecemos dois museus (Museu da Língua Portuguesa e 
REVISTA X, Curitiba, volume 13,n.1,p. 161-167, 2018.

Dossiê Especial: Português como Língua Adicional em contextos de minorias:

(co)construindo sentidos a partir das margens

BIZON \& DINIZ (Orgs.)

Museu Afro-Brasileiro), fomos a um restaurante e assistimos a um ensaio de uma escola de samba. Escrevemos e apresentamos oralmente relatos sobre essas experiências. Nas férias de verão, foi planejado um curso de extensão em que tivemos um acompanhamento que nos ajudasse a nos aproximarmos da produção acadêmica. Foi uma experiência bem enriquecedora, no sentido de que, no final das aulas, todo mundo podia se virar um pouco melhor na língua. Posso dizer que a maioria, para não dizer todos, teve bom rendimento.

Porém, mesmo considerando que estávamos no Brasil para estudar em uma universidade, acho que o grupo foi submetido apenas a um registro do português, faltando um pouco da língua do mundo cotidiano, não acadêmico. Tanto é que, em vários contextos, brasileiros ficaram surpresos com o português que os integrantes do grupo estavam usando, o que dificultava um pouco certa fluidez em nossas conversas fora do âmbito acadêmico.

Além disso, sinto que, apesar dos vários esforços feitos para que o ensino da língua não fosse restrito apenas ao conteúdo de um manual didático, faltou certa interação do grupo com os outros estudantes brasileiros, e com o entorno. No que diz respeito à moradia para os integrantes do grupo, havia certa barreira na interação, considerando que uma parte bem grande do grupo (21 de 40) ficou numa casa onde só havia haitianos. Os demais haitianos, embora alocados em casas com brasileiros, também ficavam muito entre si. Assim, passamos a maior parte do nosso tempo conversando em nossa língua materna, o que prejudicou consideravelmente a aquisição da língua portuguesa. Acredito quem se a moradia tivesse sido planejada de forma (por exemplo, se uma família brasileira ou uma casa de estudantes brasileiros recebesse um ou dois integrantes do grupo), isso ajudaria não somente na aquisição da língua, mas também na maior familiarização com outros elementos interessantes da cultura do país o que, no final das contas, favoreceria a inserção dos integrantes do grupo não somente nas construções culturais brasileiras de forma geral, mas também no meio universitário.

Eu diria que, embora tenha dado ao grupo as bases necessárias para poder se virar aqui no Brasil de forma geral, o curso de língua portuguesa deveria ter tido outros encaminhamentos, considerando questões relativas ao ensino do português para fins 
R E V IS T A X, Curitiba, volum e 13,n.1, p. 161-167, 2018.

Dossiê Especial: Português como Língua Adicional em contextos de minorias:

(co)construindo sentidos a partir das margens

BIZON \& DINIZ (Orgs.)

acadêmicos. Se não fossem iniciativas individuais de alguns professores nos oferecendo aulas de extensão durante as férias para introduzir o grupo na produção acadêmica em português, acho que o grupo teria enfrentado muitas mais dificuldades para se envolver com as atividades universitárias.

A meu ver, a falta de planejamento mais adequado é parte do despreparo da sociedade brasileira - e de tantas outras - para o acolhimento de estrangeiros de países periféricos e semiperiféricos tanto no contexto acadêmico, quanto na sociedade mais ampla. Por outro lado, a aprendizagem do português foi e continua sendo uma experiência enriquecedora e única, com a qual venho ampliando as possibilidades de enxergar o mundo, construindo meu presente e pensando meu futuro 